\title{
Critically Ill Obstetric Patients Treated in Intensive Care Unit: a Study in a Tertiary Care Institution
}

\author{
Roksana Haque ${ }^{1}$, Md. Mizanur Rahman², Showkat Jahan³ ${ }^{3}$ Kohinoor Begum ${ }^{4}$
}

\begin{abstract}
Background: The complications of pregnancy and childbirth are the leading causes of death and disability of reproductive age in developing countries. So, care of critically ill pregnant patients is an important aspect of obstetric services delivered in a tertiary care hospital. Objective: This study was conducted to find out the proportion of obstetric patients treated in ICU over a period of one year, to ascertain the frequency of serious diseases, to identify the risk factors and to determine the maternal mortality of ICU treated patients with an aim to identify the importance of a separate ICU to be incorporated within the labor and delivery suites. Materials and method: This retrospective study was conducted in Dhaka Medical College Hospital (DMCH), Dhaka, Bangladesh, during the period from January 2008 to December 2008. Total obstetric patients from all four maternity units admitted in ICU were 52 in number. Evaluation of the cases was done from records of obstetric patients treated in ICU. Necessary information was collected in a predesigned clinical sheet and the findings were compiled and necessary statistical analysis was done using SPSS. Results: ICU admission of obstetric patients in the year 2008 in DMCH was $0.82 \%$ of total deliveries and total obstetric population represented $14.3 \%$ of total ICU population. The main primary factors for ICU transfer were complications of eclampsia (59.6\%) and obstetric haemorrhage (26.9\%). The common final causes of ICU transfer were pulmonary oedema (35.5\%) in eclamptic women and haemorrhagic shock (66.7\%) in non eclamptic women. A total of $39(75 \%)$ patients died in ICU. The major cause of death was pulmonary oedema (45.5\%) in eclamptic patients and haemorrhagic shock (47.1\%) in non eclamptic patients. Conclusion: Thorough evaluation of cases has revealed that many patients needed ICU treatment which could not be provided because of limited facilities. So, incorporation of a separate obstetric ICU in DMCH could be an important component of measures aimed to reduce maternal mortality rate (MMR).
\end{abstract}

Keywords: Obstetric patients; ICU; critically ill.

Delta Med Col J. Jan 2017;5(1):15 - 19

\section{Introduction}

Despite therapeutic advances during this century and a growing perception of the safety of childbirth, still morbidity and mortality continue to occur in obstetric patients. ${ }^{1}$ The complications of pregnancy and childbirth are the leading causes of death and disability of reproductive age in

1. Associate Professor (cc), Dept. of Obs \& Gynae, Nightingale Medical College \& Hospital, Ashulia, Dhaka, Bangladesh.

2. Associate Professor (cc), Dept. of Medicine, Nightingale Medical College \& Hospital, Ashulia, Dhaka, Bangladesh.

3. Associate Professor, Dept. of Obs \& Gynae, Comilla Medical College \& Hospital, Comilla, Bangladesh.

4. Professor, Dept. of Obs \& Gynae, Popular Medical College, Dhaka, Bangladesh.

Correspondence: Dr. Roksana Haque. e-mail: rhaque21@yahoo.com 
developing countries. Every minute, a woman dies because of complications in pregnancy and childbirth - that is 585,000 women a year. ${ }^{2} \mathrm{WHO}$ report says 1 out of 16 women in Africa faces a lifetime risk of maternal death compared to 1 in 65 in Asia, 1 in 130 in Latin America and just 1 in 1400 in Europe and 1 in 3700 in North America. ${ }^{3}$

Critically ill patients are those who have acute life threatening complications. ${ }^{4}$ Manifestations of critical illness are circulatory failure or shock, respiratory failure, renal failure, disseminated intravascular coagulation, coma and septicemia. Once identified, they have to be transported to intensive care unit finally which is life-saving for many patients. In the most seriously ill patients, however, mortality rates are high. Care of critically ill patients is an important aspect of obstetric services delivered in a tertiary care hospital. 5 If adequate care can be provided to critically ill obstetric patients in time, many morbidities and mortalities can be avoided.

Pregnancy represents a unique alteration in physiology that usually proceeds to its completion without complication; however in certain instances, complications, sometimes life threatening, occur that require intensive care with invasive monitoring and mechanical ventilation. The obstetric population is usually younger than general ICU population. Despite their youth they are found to have a similar mortality. ${ }^{6}$

Dhaka Medical College Hospital (DMCH) is a tertiary referral hospital where patients from all areas of the country reach to receive adequate and prompt treatment particularly when the cases are complicated and at risk of death. Many of these patients need an intensive care service. During this study period there were only 8 beds in intensive care unit. Now the number of beds has been increased to 20, but this is also insufficient to deal a large number of critically ill patients admitted in this hospital. Many critically ill obstetric patients need ICU management but the services are inadequate many a time. So, $\mathrm{DMCH}$ has been selected as the study place to provide a valuable source of information regarding ICU use and outcome and that could influence the decision makers whether to incorporate separate ICU services for critically ill obstetric patients.

Main aim of this study is to identify the importance of a separate ICU to be incorporated within the labor and delivery suites. The specific objectives of this study were to find out the proportion of obstetric patients treated in ICU over a period of one year, to ascertain the frequency of serious diseases among obstetric patients who required ICU treatment, to identify the associated risk factors and to determine the maternal mortality of ICU treated patients.

\section{Materials and method}

This retrospective observational study was done in Dhaka Medical College Hospital (DMCH), Dhaka, Bangladesh from January 2008 to December 2008 and included obstetric patients from all four maternity units admitted in ICU for treatment during the study period. Total number was 52 obstetric patients admitted in ICU with complications like pulmonary edema, ARDS, CVA, hemorrhagic shock, and renal failure.

Evaluation of the cases was done from records of obstetric patients treated in ICU. After taking permission from hospital authority the records were collected from record room of $\mathrm{DMCH}$. Necessary information were collected in a predesigned clinical sheet and the findings were compiled and necessary statistical analysis was done using computer based software SPSS (Statistical Package for Social Science). Finally the results have been shown in different tables and figures.

\section{Limitations of the study}

As this is retrospective study necessary information were incomplete in many records particularly the underlying causes of death. As the record keeping system of this institution is poor, 
isolation of case records was too troublesome. There is no definite system of keeping the files. No computer is available in the record room. So, if all critically ill obstetric patients can be evaluated thoroughly, many more important information can be obtained which may help the policy makers to take steps to incorporate separate ICU into labor and delivery suite.

It is also important to mention that this study has not included the many other patients who required ICU care but, due to limitation of ICU beds they could not be admitted and treated in ICU. Finally, because the study was conducted over a period of only 1 year in a tertiary care centre the results may not reflect the real picture of the whole country. A large scale study is needed to reach to a definitive conclusion.

\section{Results}

Out of 6377 obstetric cases in DMCH during the study period, proportion of patients treated in ICU was $52(0.82 \%)$ and which was $14.3 \%$ out of 364 patients admitted in ICU.

The mean \pm SD age in eclamptic patients was $24.19 \pm 6.05$, whereas in non eclamptic patients it was $30.67 \pm 6.10$. This age distribution is highly significant $(p<0.001)$. In the study, most of the eclamptic patients $(58.1 \%)$ were between $21-25$ year of age and only $12.9 \%$ patients were above 30 years of age whereas majority (42.9\%) of non eclamptic patients belonged to $>30$ age group. Most of the patients requiring ICU treatment had 1-2 children both in eclamptic (48\%) and non eclamptic $(52.4 \%)$ patients.

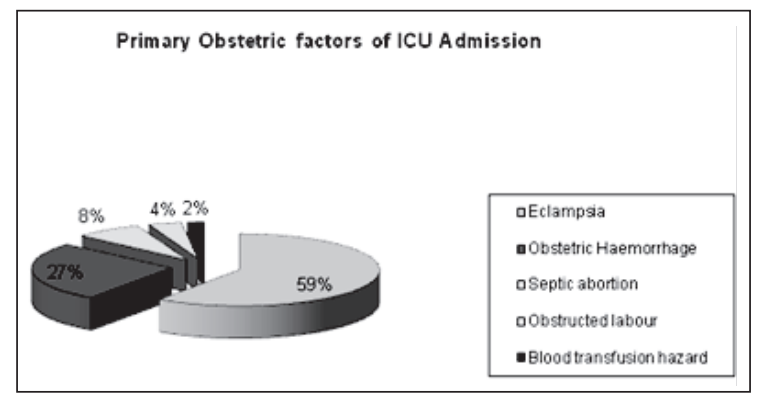

Fig. 1: Primary obstetric factors of ICU admission
Table I: Final causes for ICU admission $(n=52)$

\begin{tabular}{lcccc}
\hline Causes & $\begin{array}{c}\text { Eclamptic(n=31) } \\
\text { Frequency }\end{array}$ & $\begin{array}{c}\text { (\%) } \\
\text { Non-eclamptic(n=21) } \\
\text { Frequency }\end{array}$ & $\mathbf{( \% )}$ \\
\hline Pulmonary edema & 11 & 35.5 & 1 & 4.8 \\
ARDS & 8 & 25.8 & 0 & - \\
CVA & 5 & 16.1 & 0 & - \\
Cardiac arrest & 3 & 9.7 & 1 & 4.8 \\
Renal failure & 2 & 6.5 & 0 & - \\
HELLP Syndrome & 1 & 3.2 & 0 & - \\
Septic shock & 1 & 3.2 & 5 & 23.8 \\
Hemorrhagic shock & 0 & & 14 & 66.7 \\
\hline
\end{tabular}

This table shows that pulmonary edema was the main cause of ICU admission in eclamptic patients. Hemorrhagic shock was the main cause of admission in non eclamptic patient.

Table II: Sociodemographic profile $(n=52)$

\begin{tabular}{lccl}
\hline Parameters & $\begin{array}{c}\text { Eclamptic } \\
(\mathbf{n}=\mathbf{3 1})\end{array}$ & $\begin{array}{c}\text { Non-eclamptic } \\
(\mathbf{n = 2 1})\end{array}$ & p value $^{\mathbf{a}}$ \\
\hline Age (years) & & & \\
Mean \pm SD & $24.19 \pm 6.05$ & $30.67 \pm 6.10$ & $<0.001 * * *$ \\
Range & $18-40$ & $19-45$ & \\
Parity & & & \\
Mean \pm SD & $0.90 \pm 1.14$ & $1.52 \pm 1.29$ & $>0.05 \mathrm{~ns}$ \\
Range & $0-5$ & $0-4$ & \\
\hline
\end{tabular}

a Unpaired Student's ' $t$ ' test

Table III: Final outcome of obstetric patients treated in $\operatorname{ICU}(n=52)$

\begin{tabular}{lccccccc}
\hline Outcome & \multicolumn{3}{c}{$\begin{array}{c}\text { Eclamptic (n=31) } \\
\text { No. }\end{array}$} & $\begin{array}{r}\text { Non-eclamptic }(\mathbf{m}=\mathbf{2 1}) \\
\text { (\%) }\end{array}$ & \multicolumn{2}{c}{ Total } & \multicolumn{2}{c}{ p Value } \\
Survived & 9 & 29.0 & 4 & 19.0 & 13 & 25 & $>0.10 \mathrm{~ns}$ \\
Expired & 22 & 71.0 & 17 & 81.0 & 39 & 75 & \\
\hline
\end{tabular}

a Chi-square test

This table shows that $75 \%$ patients expired in ICU.

Table IV: Final Causes of death $(n=39)$

\begin{tabular}{lcccc}
\hline Cause & \multicolumn{2}{c}{$\begin{array}{c}\text { Eclamptic (n=22) } \\
\text { No. }\end{array}$} & \multicolumn{2}{c}{$\begin{array}{c}\text { Non-eclamptic (n=17) } \\
\text { No. }\end{array}$} \\
\hline Pulmonary edema & 10 & 45.5 & 0 & - \\
CVA & 7 & 31.8 & 0 & - \\
Multiple organ failure & 2 & 9.1 & 1 & $(5.9)$ \\
Renal failure & 2 & 9.1 & 3 & $(17.6)$ \\
DIC & 0 & - & 3 & $(17.6)$ \\
Hemodynamic instability & & & & \\
$\quad$ Hemorrhagic shock & 0 & - & 8 & $(47.1)$ \\
Septic shock & 1 & $(4.5)$ & 2 & $(11.8)$ \\
\hline
\end{tabular}

This table is showing that pulmonary edema (45.5\%) was an important cause of death among eclamptic 
patients whereas hemorrhagic shock (47.1\%) was the common cause of death among non eclamptic patients.

\section{Discussion}

Care of critically ill pregnant patient is an important aspect of obstetric services delivered in a tertiary care hospital. During the study period, total deliveries in all four maternity units in DMCH were 6377 and a total of 52 patients were shifted to ICU. The rate of ICU admission was $0.82 \%$ of total deliveries i.e; 8.2 in every 1000 deliveries. The rate is quite high in comparison to the other studies. In a study conducted in New Delhi, India by Tripathi et al. ${ }^{5}$ it has been found that the rate of ICU admission was 1 in 540 deliveries. In many other studies ICU admission rate was lower. ${ }^{7,8}$

The higher incidence in our country in comparison to developed countries probably is due to poor socio economic status, lack of education, gender issue against women which causes delay in seeking medical help. In some circumstances, the health care facilities are not equipped with staff, facilities and transport systems. The patients are referred only when complicated in severe form.

This study shows that the obstetrical population represents $14.3 \%$ of the total ICU admitted patients. So, the rate is quite high in our set up in comparison to other studies. ${ }^{9}$

Eclampsia had been found to be the commonest cause of ICU admission (59.6\%), 2nd in order was obstetric hemorrhage $(26.9 \%)$ and the 3 rd was septic abortion (7.7\%). In many other studies also the main cause of ICU admission was found to be hypertensive disorders of pregnancy reflecting the fact that hypertensive disorders are still the most important obstetric causes of maternal mortality and morbidity. $1,8-10$ The proportion of eclamptic patients may be higher in $\mathrm{DMCH}$ as it is a tertiary referral hospital having a separate eclampsia unit with adequate facilities to manage the eclamptic patients.
As most of the study populations were eclamptic, so the findings have been evaluated comparing the eclamptic with the non eclamptic population which includes obstetric hemorrhage, septicemia and others. In eclamptic patients, pulmonary edema (35.5\%) was the main final cause of ICU admission and ARDS (25.8\%) was 2nd in order. Pulmonary edema accounted for respiratory failure in 5 out of 12 patients in another study. ${ }^{6}$

A total of 39 (75\%) patients out of 52 expired. Among these, 22 (42.3\%) patients were eclamptic and $17(32.7 \%)$ patients were non eclamptic. In a study by Collop et al. maternal death was only $20 \%$ whereas in India, maternal death was $28 \%$. 5,6 Maternal mortality is too high in our set up. This is a reflection of high maternal mortality rate (MMR) in our country and may be due to poverty, illiteracy, lack of ante natal care, delay in seeking medical care, late referral, inadequate emergency obstetric care, poor transport at centers close to the patients' residence and overall limitations of facilities and even in tertiary care hospitals like $\mathrm{DMCH}$.

Pulmonary edema (45.5\%) and CVA (31.8\%) were the common final causes of death among eclamptic patients whereas; hemorrhagic shock $(47.1 \%)$ was the main cause of death in non eclamptic patients. Tripathi et al. ${ }^{5}$ showed that maternal death was mainly due to DIC and hemorrhagic shock. In many other studies causes of death were shock, sepsis, preexisting medical disorders, and multiple organ failure. ${ }^{6,9}$ There are many studies in this country on eclampsia revealing that CVA and pulmonary edema were common causes of maternal death in eclampsia. ${ }^{11-13}$

\section{Conclusion}

Multidisciplinary critical care medicine has evolved substantially in the last three decades and there have been major changes in the organization of services and environment of care of the critically ill patients. In the developed countries, 
the maternal death rates have been reduced to less than 1 percent by proper utilization of resources and services. ${ }^{2}$ Bangladesh is a developing country where the maternal mortality rate is high which was 3.22/1000 live births during the study period. It has been decreased to $1.94 / 1000$ live births during 2007-2010. ${ }^{14}$ Many patients present in the health care facilities in complicated form and often require an intensive care service. But the facilities are inadequate even in the tertiary care centre like DMCH.

Thorough evaluation of cases in this study and in several previous studies has revealed that many patients needed ICU treatment, which could not be provided because of limited facilities. ${ }^{12,13,15}$ There were only 8 beds to manage all critically ill patients of this big hospital which seemed inadequate many a time. This information may be of interest to the health care providers and policy makers to decide whether to incorporate a separate obstetric ICU in DMCH which could be an important component of measures aimed to decrease MMR.

\section{Acknowledgement}

We are thankful to the Director, Dhaka Medical College Hospital to provide kind permission to have access in Record Room to collect data. We must express gratefulness to the staff of record room, patients, nurses and physicians of $\mathrm{DMCH}$ whose sincere cooperation made this study possible.

\section{References}

1. Panchal S, Arria AM, Harris AP. Intensive Care Utilization During Hospital Admission for Delivery: Prevalence, Risk Factors and Outcomes in a Statewide Population. Anaesthesiology. 2000;92(6):1537-44.

2. Revised 1990 Estimates of Maternal Mortality: A New Approach by WHO and UNICEF. World Health Organization; Geneva. 1996.
3. CNN - Global Conference Focuses on Pregnancy Related Death. 2003 June 11 (cited 2009 Aug 5). Available from: http://www.cnn.com/health/ 9804/07/worldhealthday/11/6/2003.

4. Rab OA. Critical Care. The Square Healthcare Bulletin. 2005;13(1):11-16.

5. Tripathi R, Rathore AM, Saran S. Intensive Care for Critically Ill Obstetric Patients. International Journal of Gynaecology and Obstetrics. 2000;68:257-58.

6. Collop NA, Sahn SA. Critical Illness in Pregnancy an Analysis of 20 Patients Admitted to a Medical Intensive Care Unit. Chest Journal. 1993;103(5):1548-52.

7. Baskett TF, Sternadel J. Maternal Intensive Care and Near-Miss Mortality in Obstetrics. British Journal of Obstetrics and Gynaecology. 1998;105:981-84.

8. Quah TC, Chiu JW, Tan KH, Yeo SW, Tan HM. Obstetric Admissions to the Intensive Therapy Unit of a Tertiary Care Institution. Ann Acad Med Singapore. 2001;30(3):250-53.

9. Hazelgove JF, Price C, Pappachan VJ, Smith GB. Multicentre Study of Obstetric Admissions to 14 Intensive Care Units of in Southern England. Critical Care Medicine. 2001;29(4);770-75.

10. Olarra J, Longarela AM, Suarez L, Palacio FJ. Critically Ill Obstetric Patients Treated in an ICU. Chest Journal. 2002;121(6):2077.

11. Yasmin N. A Critical Analysis of Crisis of Eclampsia in DMCH - a 1 Year Study [dissertation]. Dhaka: BCPS; 2004.

12. Begum S. Eclampsia Related Mortality: Critical Review of Clinical Profile and Treatment Pattern at DMCH [dissertation]. Dhaka: BCPS; 2005.

13. Khatun K. Critical Review of Maternal Deaths - A 1 Year Study in DMCH [dissertation]. Dhaka: BCPS; 2005.

14. Arifeen SE, Hill K, Ahsan KZ, Jamil K, Nahar Q, Streatfield PK. Maternal Mortality in Bangladesh: a Countdown to 2015 Country Case Study. Lancet. 2014;384(9951):1366-74.

15. Shaheen N. Maternal Mortality and Severe Morbidities in Association with Eclampsia: A 1 Year Retrospective Study in a Tertiary Care Centre [dissertation]. Dhaka: BCPS; 2005. 